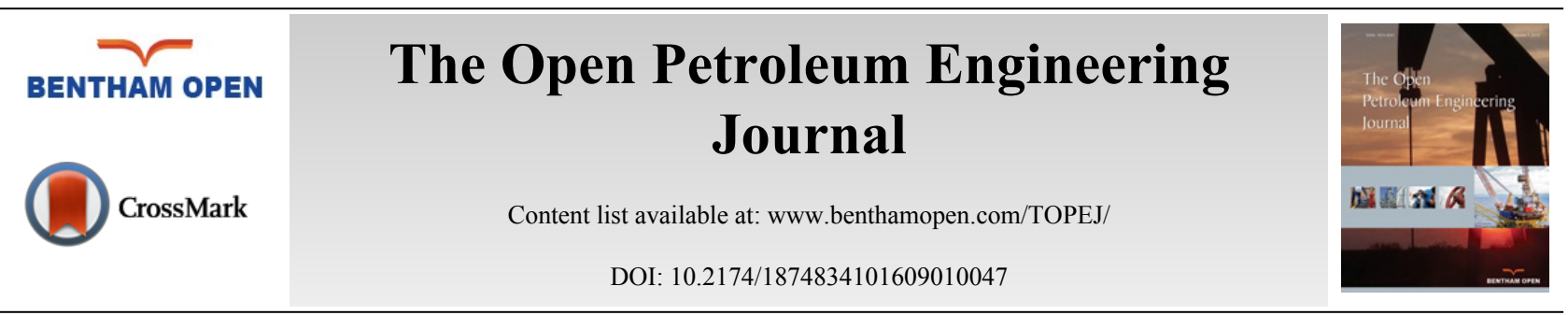

REVIEW ARTICLE

\title{
Global Energy Demand and Its Geopolitical and Socioeconomic Implications: Which Role Would Shale Resources Have?
}

\author{
Carlos Castro*, Francesca Verga and Dario Viberti
}

Politecnico di Torino, Italy

Received: October 4, 2015

Revised: July 21, 2016

Accepted: August 8, 2016

\begin{abstract}
This paper discusses the geopolitical and socioeconomic implications the development of shale gas ( $\&$ oil) has had in the US. The approach has been that of placing shale gas under erasure (or sous rature). In other words, the assumption that shale is currently both present/absent was made to answer the question of whether it can actually be considered as a resource. Moreover, the success of the "shale revolution" in the US has not only had an impact on the International Oil \& Gas, Petrochemical, natural resource and renewable markets, but it has also triggered certain geopolitical events which are modifying the role played by nations globally. Finally, it is suggested that under the prevailing circumstances these unconventional resources appear to still be more of a challenge than part of the solution to the ever growing energy demand, and production of goods associated with societal needs/aspirations worldwide.
\end{abstract}

Keywords: Energy, Geopolitics, Horizontal drilling, Hydraulic fracturing, Shale.

\section{INTRODUCTION}

Every single sector of modern society can be held accountable for today's energy crisis. Nowadays, our independence of judgment could be so restricted that even scientific thinking (its constructive-speculative character at least) has simply become trained thinking. Arguably, this paper aims to be the consequence of total - though partial may be more realistic - independence of judgment. It would make little sense to dwell upon how we got into this mess in the first place, interestingly enough every generation has somehow been able to undermine and so put off the immediacy of the energy crisis since the 1960s (generational stalling has been passed on instead); hence, our concern is not so much what happened or what will/can happen, but instead what is happening. This paper will address specific aspects of the so-called "shale gas revolution" that has been taking place in the United States (US). As it often happens when trying to write about contemporary events, there is none to very little advantage of hindsight, at best this paper cannibalizes papers and documents being published as the writing was taking place. One way to better understand the current implications of the "shale gas revolution" is by placing it under erasure, which is to say, by writing about it and striking through it to show how necessary and yet inadequate this revolution - as all revolutions are - looks at the moment. Consequently, this investigative approach highlights the presence/absence condition of shale that leads to the question: is shale a resource or not?

According to one of the many International Energy Agency (IEA) reports (2014) over \$1600 billion is being invested each year to provide the world's consumers with energy [1]. Interestingly, this report also says that approximately $70 \%$ of said investment is related to fossil fuels (which provide around $80 \%$ of the world's energy demand), be it for oil, gas or coal extraction, transport to consumers, transformation (e.g. from crude oil to refined oil products), or the construction of fossil-fuel fired power plants. However, with so many oil fields reaching their maturity, finding new and/or alternative resources has become a must. Shale gas has been seen as a possible solution, albeit

\footnotetext{
* Address correspondence to this author at the Dipartimento di Ingegneria dell'Ambiente, del Territorio e delle Infrastrutture (DIATI) Politecnico di Torino, Corso Duca Degli Abruzzi 24, 10129 Torino, Italy; Tel: +390110907727; E-mail: carlos.castro@polito.it
} 
success stories are limited to a handful of basins in the US and Canada where natural gas and oil from shale formations are produced on a commercial scale even if in aggregate investment is still more than the earnings [1]. For years, the technical literature has focused on shale as if they were truly the solution (or to a large extent at least) of our energy needs. Perhaps a good way to sum up today's state of misinformation surrounding the "shale gas revolution" would be by looking at how it is being interpreted/characterized by different sectors of society (namely political, technological and economical) which, unfortunately, seem always more disconnected from each other. The reader is reminded though that any worldwide view on shale can only be seen through the lens of the US experience which is ultimately the sole global reference on the matter thus far.

\section{The Politics of Energy - Non-Geological Considerations}

From a political viewpoint, the current US administration is not only enjoying shale gas success (though exploration and development started long ago) but it is also seizing the opportunity to recast the US role in the global energy landscape. Not surprisingly the government wants to create 'Sustainable Shale Gas Growth Zones' in what seems to be a strategy to require cross-subsidies from shale gas to renewables as a condition for development (in other words fossil fuels would be subsidizing renewables). Inevitably the question as whether shale gas is actually sustainable arises. Otherwise, why the cross-subsidies (or feebates)? On a finite planet, such as ours, having just one main source of energy has meant a downward spiral (even more so since the Industrial Revolution because development has been largely driven by fossil fuels). The history of energy supply-and-support systems is out of the scope of this paper (on this subject readers may find useful the first chapters of Jeremy Rifkin's The Hydrogen Economy), but to fully grasp the seriousness of the situation some concepts must be made clear and so a short digression is at hand.

For many experts past historical events help define present ones, yet when it comes to the ever confusing "politics of energy" nothing short of the current state of international affairs, or simply how-are-we-getting-along-today scenario, can determine the everyday life of the large majority of the world's population. Politics may be too close to philosophy for science, but let us not forget from where science stems. Perhaps in an over simplistic - yet logically and critically thought - manner the following should be kept in mind throughout this paper: energy empowers politics. Consequently, energy is politically contested, both nationally and internationally; and, as far as energy supply is concerned, oil continues to be the most vulnerable to geopolitical risks. To prove this an account of one of the many events that developed at the time of writing should suffice.

In October 2014, when oil prices dropped to below US\$90 per barrel, oil market participants began to wonder when the Organization of the Petroleum Exporting Countries (OPEC) would step in and cut down production to re-boost prices back over the US\$100 mark. However, a statement by Saudi Oil Ministry spokesman Ibrahim al-Muhanna made it clear OPEC leader Saudi Arabia was in no rush to scale down production simply because "the high cost of producing shale oil had put a floor under oil prices" [2]. The production costs of shale oil ${ }^{1}$ (the new frontier) and shale gas (fields decline so fast it's now old news) are high compared with conventional resources because of the capital-intensive nature of the technology involved, namely hydraulic fracturing (aka fracking) and horizontal drilling. At present, the major drawback of nearly all unconventional resources is their high production costs. Politically speaking, there seems to be a shale paradox in the US: can the US actually become energy independent by relying on the output of an unconventional resource whose very production is so dependent on the fluctuations of oil prices? The two main (opposing) political parties agree the US should be energy independent, though they disagree on how this can be done realistically. For instance, while one party believes renewable/alternative energy to be the answer, the other continues to bet on (conventional and/or unconventional) fossil fuels. Interestingly, both resources are, and contrary to popular belief, intrinsically related.

Though fossil fuels provide cheap energy, as compared to renewables, they also have an arguably greater impact on the environment (e.g. climate change). Contradictorily, renewables turn out to be expensive because they depend on fossil fuel for energy. Energy provided by solar panels may have low environmental impact, but not the actual making of solar panels considering the energy needed comes from "burning" fossil fuels. Still, one could ask whether the energy to manufacture the panels could come from other solar panels. Sadly, the fact remains that the payback time of renewable energy is often measured in decades, but more and more energy is needed every day to move and transform things. This is a major conundrum for most, as it poses the question of whether a full scale shift from one form of

\footnotetext{
${ }^{1}$ The expression "shale oil", or the more accurate term "tight oil", is often used to refer to rock formations that contain oil and might sometimes actually be shale [3].
} 
energy to another is likely. Think, for instance, that electric cars are a reality, but modern society also requires long-haul trucks to transport goods across countries (move-and-transform-things society), could they also be powered by electricity? The "politics of energy" can be confusing precisely because of the complex and seemingly unrelated connections between factual and speculative knowledge, small wonder there are so many "energy writers" out there trying to set records straight. In the US, political debates revolving around energy have ended up caught in the kind of political rhetoric that masks reality and makes deciding the best choices available a now-it's-too-late-for-that situation.

What role is shale playing in the current American energy mix? As suggested by OPEC's (non)reaction to tumbling crude prices, it would appear that shale has recast the US in the role of "swing producer". And though this may have brought back a smile to most folks in Capitol Hill, the situation today is far from that of the Arab-Israeli conflicts of the 1950s and 1960s in which the US's swing-producer role was government-driven as opposed to price-driven. Of course, a political smile is not a technical one, here is a reality check: experts say US shale oil production costs are somewhere in between US $\$ 85 / \mathrm{bbl}$ to US $\$ 110 / \mathrm{bbl}$ whereas Saudi crude costs are a meager US\$10/bbl, or US\$15 at the most [1, 4]. Even shale gas is costly when natural gas prices drop, add fast declining fields (unarguably technology won't make up for lesser-quality geology) and uncertain environmental impact to the equation, and the shale revolution is already a thing of the past [5]. Shale gas and oil do not seem to be a bridge to move energy production away from coal and oil. From this perspective and under these specific historical circumstances, other than swing producer the US is looking more like a "wring producer" as it tries to squeeze out every single drop of oil it can just to stay in the game.

Seen from a different angle the above said could also paint an entirely different picture. What if keeping low oil prices was intended to further weaken certain world economies? A geopolitical dispute - though it would be more accurate to say a supposedly unpaid gas bill - between Ukraine and Russia (any peace roadmap for the parties involved will definitely be a rocky one) led to economic sanctions on behalf of Europe and the US to the latter. In this case, a US\$20 oil-price drop alone might not be enough to make Russian economy stumble, but not being able to borrow money from outside the country would pose a serious threat to economic stability. Some analysts have suggested this situation would only drive Russia closer to China (allegedly in May 2014 China signed a multi-billion dollar gas deal with Russia followed by a number of economic agreements [6]). Europe would be significantly affected given its high dependence on Russian gas. In this case, the US could consider exporting liquefied natural gas (LNG) to Europe, albeit all the implied complexities of doing so.

As far as energy supply is concerned, nowadays, Europe and the US consume nearly $50 \%$ of net imports of oil which means they are susceptible to disruptions in oil supply as well as price fluctuations [5]. In the US, the unanswered question still remains: can shale gas (and oil) be a permanent solution to a temporary problem or, quite the opposite, just a temporary solution of a long-lasting problem? Europe is certainly skeptical about the shale gas revolution in the US (Poland's failed experiment to extract shale gas has had its toll) and yet it somehow sees with high hopes going from Russian-gas dependent to American-gas dependent. Geopolitical risks concerning energy supply have much to do with the paradox that a country's development is fossil-fueled, somehow reinforcing the idea that a country is only as strong as its capacity to build. However, and much to the regret of many, politics cannot fix geology. Engineering, on the other hand, has been known for trying to patch it up.

\section{The Technologies Behind the Shale Revolution: A Few Engineering Considerations}

It has been argued that the current success of shale gas (and lately shale oil) extraction is largely due to the combination of hydraulic fracturing and horizontal drilling. The importance of these technologies in shale gas production has been corroborated by a large majority of experts; in fact, the American Petroleum Institute (API) states that the fast rise in production from shale formations in the US "is attributable to significant advances in the use of horizontal drilling and well stimulation technologies and refinement in the cost-effectiveness of these technologies" and "hydraulic fracturing is the most significant of these" [7]. It is also true this technology is not new to the oil and gas industry as the first fracking experiment was performed in 1947 and became commercial by 1950 [8], on the other hand, horizontal drilling dates back to the first horizontal well in the 1930s and horizontal wells were common by the 1990s $[8,9]$. Sound engineering practice recognizes that fossil fuel extraction could have negative consequences for the local environment in which it takes place and hence poses risks. Nonetheless, some academic observers have concluded that if properly carried out, fracking, for instance, may have lower risks than one might think [10]. Recently, Rubinstein and Mahani [11] have argued that compared with wastewater disposal, fracking is less responsible for inducing earthquakes. In fact, the evidence shows that out of the tens of thousands of wells which are fracked every year in the US, only a few dozen are known to have induced felt earthquakes. Paradoxically, both critics and defenders of fracking have valid 
arguments to support their opposing views. This section of the paper, however, will look at the technology used to produce gas (or oil) from shale formations strictly from an engineering viewpoint.

As it is well-known, shale gas falls under the category of unconventional resources along with shale oil, tight gas, coalbed methane (CBM), heavy oil/tar sands and methane hydrates. Technical papers covering 30 years or more of shale technology development show that only shale formations with certain characteristics will produce gas [8, 12, 13]. Perhaps the two most distinctive features of shale formations are: 1) the shale acts both as the source and the reservoir for the natural gas; and 2) shale permeabilities range from 1 to over 100 nanoDarcies, for reference, construction-grade cement averages about $0.005 \mathrm{mD}$ [8]. (Just picture trying to extract water from an ordinary blackboard and yes the now old classroom type!). In these places conventional technologies are ineffective and this is where fracking comes in. Basically, the mechanism involves the use of water pressure to create fractures (or cracks) in the rock to release the oil and natural gas it contains into wells that have been drilled for collection. In engineering practice, fracking refers to this specific stimulation activity; in other words, it is limited to the fluid action in initiating and extending cracks in the rock [8]. Whether willingly or not, to the untrained eye, fracking has come to represent nearly every phase of the well development cycle; i.e., from drilling to production. To a large extent, this situation has (de)generated (into) the many inaccuracies surrounding hydrocarbon production from shale formations. Hydraulic fracturing technology was introduced and developed to help solve an undesirable condition (i.e., low-permeability rocks) or, in other words, to bridge the gap between what is and what is desired. As it happens with many other technologies, hydraulic fracturing has been undergoing improvements which have made its application progressively safer, albeit large amounts of water usage continues to be a problem. In the US, this process (now) takes place under tighter and tighter regulatory control than when it was first implemented. Small wonder the focus of much of the research carried out today continues to revolve around the benefits of additional safeguards (popular wisdom says "you can never be too safe!"). A recent paper, for instance, has emphatically suggested increasing safeguards when hydraulic fracturing is carried out at shallow depths (according to the authors less than one mile as far as the US is concerned) to make sure the technology does not impact drinking water reservoirs [14].

As aforementioned, horizontal drilling is the other technology directly involved in the US shale boom. As opposed to fracking, horizontal drilling has largely been ignored by the media (it does not seem to induce "earthquake" news!) and general public, and thus not as negatively targeted as its technological counterpart. It is particularly common in shale reservoirs because it allows significantly more wellbore exposure to the reservoir rock. More specifically, horizontal drilling is a subset of directional drilling, i.e. the intentional deviation of a wellbore from a vertical path to a horizontal trajectory. Historically speaking, the technology can be traced back to the first US patent for the use of flexible shafts to rotate drilling bits issued to John Smalley Campbell [15, 16]. However, practical application of the technology did not truly take place until the early 1980s, when improved downhole drilling motors and the invention of downhole telemetry equipment made the technology commercially viable [16]. It may be true horizontal drilling lets producers access far more natural gas from relatively thin shale deposits, nonetheless high drilling rates and associated costs play against the technology. Yet, it must also be said that over the last decade, the cost difference between horizontal and vertical drilling has been narrowing down. Consider that in Texas' Barnett shale, the US's most developed shale play, the number of producing horizontal wells rose from fewer than 400 in 2004 to more than 10,000 during 2010 as reported by the US Energy Information Administration (EIA) [17].

In short, hydraulic fracturing coupled with horizontal drilling make it possible to extract and produce natural gas in places where traditional technologies are ineffective. However, good engineering practice should not only be concerned with the integration of process and knowledge, in fact it should also address the economics of such integration. This issue has polarized analysts and experts insofar as the changes brought on by the shale revolution in the US has disrupted the existing state of affairs. Contrarians for instance, as analyst and author Bill Powers or geologists Arthur Berman and David Hughes, already speak of "the popping of the shale gas bubble". The main argument here is that shale gas resources and reserves have been exaggerated and highly speculative and today's level of shale gas production is unsustainable. On the other hand, there are those, for example Daniel Yergin, who believe that shale gas can lead the US to the much coveted "energy independence".

\section{Socioeconomic Implications: The Costs of Revolution}

The blessing and the curse of any type of revolution is (often) the irreversible change in the established order. The US is now producing so much gas that the market has been oversupplied, forcing gas prices sharply downwards, add the recent steady fall in oil prices and the average American consumer (keep in mind that the word 'consumer' nowadays, 
actually stands for 'oil' consumer) is now truly convinced the shale revolution is nothing short of a blessing. This may actually be true, at least for all those who do not work for the oil industry or those who do not have investments in the oil industry. Those not particularly fond of the oil and gas industry may even rejoice over the imminent gloomy times ahead, but they should also be aware the situation will have a negative impact on those who work in the renewable energy industry, or the energy efficiency business and even those addressing climate change. It is hard to accept reality, especially when it is riddled with contradictions, the likes of the oil and gas industry is a (direct or indirect) sponsor of renewable energy!

Unquestionably, energy is so central to our modern economy that when its price goes up, every other sector of the economy feels it and, whether we like it or not, fossil fuels represent the primary source of energy worldwide (according to the EIA - just in the US - petroleum, natural gas, and coal together provided $87 \%$ of total primary energy during the first decade of the twenty-first century, [18]). These are the cold, hard facts. Needless to say, energy is, and will continue to be, a corollary of fossil fuels until alternative sources can realistically replace them. To this end, and as mentioned earlier, it has been suggested shale gas and oil could lead the transition into a less fossil-fuel dependent world. However, opposers have argued that these unconventional resources cannot actually deliver. Much of the debate revolves around the commerciality of shale production given the lack of long-term production history to validate estimated ultimate production (EUR) [19]. Recently, Browning et al. [20, 21] published a study on the Barnett Shale which, among other things, tackles detailed well-by-well analysis of production and calculation of EUR for all wells. Generally speaking, it could be said that drilling projects should meet acceptable estimated EUR thresholds for a project to be considered viable and profitable. At the time of writing, for instance, US natural gas trade was below the 3\$/MMBtu (around \$2.70/MMBtu) set for the study's worst-case scenario, which the authors had claimed would be "unlikely to occur" $[17,18]$. While authors could have predicted increasing natural gas supplies in their forecast model, they could not have done so for the relatively mild weather which brings us to the problematic of virtually all forecasting, i.e., their accuracy. Up until now, experts have addressed this particular issue without consensus. Interestingly, Hawking [22] has recently restated the seemingly obvious (yet too often forgotten), “one can't predict the weather more than a few days in advance" from which we can imply that long-term forecasts are rather worthless if one considers how rapidly their accuracy deteriorates the longer out into the future they go. Ideally, then, long-term forecasts should be used more as a way to characterize future risks rather than banish them; hence the focus should not be on the median projection as much as on the range insofar as range could tell us much more about the nature of the risks we face [23]. But, what does all this seemingly disconnected narrative actually mean?

Essentially, it means all sides involved have chosen to handpick only the evidence supporting their own previous opinions and beliefs (aka confirmation bias). Surely, this is not the only mechanism at work, but it is the one largely responsible for the narrowing of our minds (and let us not forget scientific thinking entails thinking open-mindedly). No doubt oil and natural gas extraction from shale has increasingly polarized society, even if through an accumulation of undigested facts. Consider the following (very general) situation: a group of elected officials must determine the course their country should take in relation to energy policies for the medium-term, to do so they analyze oil \& gas production forecasts provided by "independent" agencies (such as, the EIA or the IEA). And here lies the first of their problems, as mentioned above forecasts are difficult to handle objectively. A decision-maker's judgment under the uncertainty of forecasts may detect patterns where none exist (it is worth noting, however, that research has indicated this tendency can be observed in both experts and laypeople alike [24]); hence, an overly optimistic forecast could pose serious threats to a country's stability as actions taken on such basis tend to undermine risks. Conversely, less optimistic forecasts create the kind of panic which leads to rash decisions and regrettable actions. Small wonder both the EIA and the IEA have begun to constantly review their forecasts in an effort to present more reliable data to policymakers as well as business and governmental leaders who happen to take these forecasts quite seriously.

Heretofore what can be said about the "shale revolution" is that it is far more of an indicator than of a driver within the energy mix. But what exactly is it an indicator of? Unarguably, it highlights (for those who have not been paying attention) the fact that conventional resources are finite and unconventional ones (mind you finite too!) are much needed whether to perpetuate our current lifestyles or serve as transition into a completely different order. Moreover, and regardless of whose side one is on, pro or against the preservation of the status quo, this "revolution" has also evinced how the science is being increasingly downplayed by all other factions involved in decision-making processes. As of late company executives, politicians, investment managers - i.e., the so-called power structures in our society or bluntly those who are running our lives- are finding factual information more and more difficult to analyze and interpret. In their defense, though, those behind the science have not been as clear - or have somehow been steered to 
ambiguity - as one would want lately. Readers may want to ask themselves this: Can we actually tell what is false from what is not anymore? How many failures to prove a hypothesis can be found in scientific literature nowadays? Poor decisions can be made, but they should not be due to misleading information, especially when the stakes are so high. The ambiguities of today's decision making can be seen with the recent presidential veto of TransCanada's Keystone XL tar sands export pipeline project (running from Alberta, Canada, to Cushing, Oklahoma) by the Obama administration. In 2013, the same administration had decided to go ahead with the southern leg of this project only to now ban the northern leg, keep in mind they relied on the exact same data, mostly on environmental grounds. In fact, many will argue the evidence provided by the US Environmental Protection Agency (EPA) in February 2015 (see http://www.epa.gov/compliance/nepa/20140032.pdf) was pivotal, however, similar evidence had been presented by independent experts for the project's southern leg and it was not considered in the same manner. So, if the science had not changed, what had? Well, everything but. First and foremost, oil prices, from the $100 \mathrm{USD} / \mathrm{bbl}$ of 2013 to the 50 USD/bbl of early 2015 , suddenly making a project of this magnitude less attractive. That is to say that despite our obsession with it, the science is becoming less and less relevant in decision-making processes.

\section{CONCLUSION}

Much to the detriment of the coming generations, we have also been doing very little to clean up the mess passed on by our forebearers. Ultimately, the presence/absence of shale resources has done nothing more than simply (re)state the obvious: geopolitical hegemony, economic and social inequality, as well as confirmation and status-quo bias. The truth of the matter is that every sector involved has indulged heavily on rhetoric while being light on data. One of the questions posed by the US shale revolution has been whether or not the exploitation of such resources could serve as a 'transitory' means towards renewable energy sources. Once more, experts remain divided on the subject. On the one hand, there are those who believe shale resources are the key to US energy independence, and on the other, those who view them as a mirage on the horizon. From a technical viewpoint, the data can play in favor of either side because even critical thinking is at the mercy of our perception of facts, perception being the key word here. In recent years, most of the discussions on the subject have revolved around peer-reviewed research and the attempt to address the facts from a neutral perspective. But neutral is akin to science whereas not so much to human nature. In fact, keen observation of the development of shale shows worrisome scientific mood swings, either there's-nothing-to-worry-about or better-safethan-sorry postures.

We are all well aware of the fate that met many species in the geological past (and we are referring to those who exhausted the resources in the habitat they lived in!). A common place of our self-opinion has been "it will never happen to $u s$, we are too intelligent" and yet fact-driven thinking would appear to be saying otherwise. Whether shales become the resources some want them to be, will make little difference in the much larger context of our future on a finite planet. The real quest will be to make the systematic changes our society desperately needs. For instance, does it really make sense to foment the ways of the industrialized world in the so-called developing nations on claims that they would gain so much in terms of education, health care, technology and more? Aren't these developing nations the very consequence of the development of the industrialized world? Moreover, has anyone actually asked the people (not the leaders) of these nations whether they want to live like their wealthier counterparts? Questions like the above are readily dismissed as nonsensical by the highly educated members of industrialized society, after all who wouldn't want to live the industrial dream? Nonetheless, one cannot help but ask: who is the most resilient, who will be best fit to overcome if we ever reach the dramatic energy shortages some are predicting? Many speak about learning from past mistakes as they make those very same mistakes over again. Nowadays, a significant number of papers on shales have 'lessons learned' as part of their title, which, in a way, can be interpreted as follows: development of unconventional reservoirs (specifically of shale gas \& oil) in the US has reached a point in which reducing uncertainties is almost at the same level as that of conventional reservoirs. Needless to say, the situation of these unconventional resources in the rest of the world is far from being comparable. Only time, and the markets, will tell whether the chances the US has taken to develop shale gas and oil will eventually pay off. As far as meeting global energy demand is concerned, it seems rather certain the situation can only get more and more complex; meaning that for better or for worse the real uncertainty always lies within $u s$.

As things were (or appeared to be) up to July 2015.

\section{CONFLICT OF INTEREST}

The authors confirm that this article content has no conflict of interest. 


\section{ACKNOWLEDGEMENTS}

Declared none.

\section{REFERENCES}

[1] "World Energy Investment Outlook", Available from: https://www.iea.org/publications/freepublications/publication/WEIO2014.pdf

[2] R. McNally, "For Production Cuts, Oil Market Looks to OPEC, but OPEC looks toward US Shale", Center on Global Energy Policy | Columbia SIPA, October, 2014. Available: http://www.energypolicy.columbia.edu [Accessed: 19 ${ }^{\text {th }}$ Nov. 2014].

[3] B. Madden, and S. Vossoughi, "US shale gas and tight oil boom - The opportunities and risks for america", In: SPE Asia Pacific Oil and Gas Conference and Exhibition, 22-24 October, 2013, Jakarta, Indonesia, 2013. [http://dx.doi.org/10.2118/165770-MS]

[4] D. Lawrence, "Has OPEC check mated US shale producers", Oct. 15, 2014. Available from: http://www.resilience.org/ stories/ 2014-10-15/ has-opec-check-mated-us-shale-producers [Accessed: 16 ${ }^{\text {th }}$ Oct. 2014]

[5] D. Hughes, "Drill, Baby, Drill: Can Unconventional Fuels Usher in a New Era of Energy Abundance?", Oct, 2013. [Online]. Available from: http://www.postcarbon.org/books_and_reports/

[6] “China Media: Russia Gas Deal”, BBC News, Available from: http://www.bbc.com/news/world-asia-china-27514395 [Accessed: $22^{\text {nd }}$ May 2014]

[7] "Facts about shale gas". Available from: http://www.api.org/policy-and-issues/policy-items/exploration/facts_about_shale_gas [Accessed: $6^{\text {th }}$ Nov. 2014].

[8] G.E. King, "Hydraulic fracturing 101: What every representative, environmentalist, regulator, reporter, investor, university researcher, neighbor and engineer should know about estimating frac risk and improving frac performance in unconventional gas and oil wells", In: SPE Hydraulic Fracturing Technology Conference, 6-8 February, 2012, The Woodlands, Texas, USA, 2012. [http://dx.doi.org/10.2118/152596-MS]

[9] J.D. Arthur, B.K. Bohm, B.J. Coughlin, M.A. Layne, and D. Cornue, "Evaluating the environmental implications of hydraulic fracturing in shale gas reservoirs", In: SPE Americas E\&P Environmental and Safety Conference, 23-25 March, 2009, San Antonio, Texas, USA, 2009. [http://dx.doi.org/10.2118/121038-MS]

[10] S.L. Brantley, and A. Meyendorff, "The Facts on Franking”, The New York Times, March 13, 2013. [Online]. Available from: http://www.nytimes.com/2013/03/14/opinion/global/the-facts-on-fracking.html

[11] J. L. Rubinstein, and A. B. Mahani, "Myths and facts on wastewater injection, hydraulic fracturing, enhanced oil recovery, and induced seismicity", Seismol. Res. Lett.. June 2015. [Online]. Available from: https://profile.usgs.gov/myscience/upload_folder/ ci2015Jun1012005755600Induced_EQs_Review.pdf

[http://dx.doi.org/10.1785/0220150067]

[12] O. M. Kiel, "The Kiel Process Reservoir Stimulation By Dendritic Fracturing", Paper SPE 6984, Jan 1977.

[13] Available from :http://www.api.org/policy-and-issues/policy-items/exploration/facts_about_shale_gas [Nov., 6, 2014].

[14] R. B. Jackson, E. R. Lowry, A. Pickle, M. Kang, D. DiGiulio, and K. Zhao, " The depths of hydraulic fracturing and accompanying water use across the united states", Environ. Sci. Technol., vol. 49, no. 15, pp. 8969-8976, 2015. [http://dx.doi.org/10.1021/acs.est.5b01228]

[15] J.S. Campbell, "Flexible Driving Shaft", U.S. Patent 459,152, September 8, 1891.

[16] L. Helms, "Horizontal Drilling", North Dakota Dpt. Miner. Resour. Newslett., vol. 35, no. 1, pp. 1-3, 2008. [On-line] Available from: https://www.dmr.nd.gov/ndgs/newsletter/2008 Summer.asp

[17] "Technology Drives Natural Gas Production Growth from Shale Gas Formations", [Online]. Available from: http://www.eia.gov/ todayinenergy/detail.cfm?id=2170

[18] "ENERGY SOURCES have changed throughout the history of the United States", Available from: http://www.eia.gov/ todayinenergy/detail.cfm?id=11951 [Accessed: 26 ${ }^{\text {th }}$ Nov. 2014].

[19] D. Hughes, "Drilling Deeper: A Reality Check on U.S. Government Forecasts for a Lasting Tight Oil \& Shale Gas Boom" Oct. 2014. [Online]. Available from: http://www.postcarbon.org/publications/drillingdeeper/.

[20] J. Browning, S. Tinker, S. Ikonnikova, G. Gülen, E. Potter, Q. Fu, S. Horvath, T. Patzek, F. Male, W. Fisher, F. Roberts, and K. Medlock III, "Barnett Shale Model - 2 (Conclusion): Barnett Study Determines Full-field Reserves, Production Forecast", J. Oil Gas. Sept. 2013. [Online]. Available from: http://www.ogj.com/articles/print/volume-111/issue-9/drilling-production/barnett-study-determines-full-field-reserves.html.

[21] J. Browning, S. Ikonnikova, G. Gülen, and S. Tinker, "Barnett shale production outlook", Soc. Pet. Eng., vol. 3, no. 5, 2013. [Online]. Available from: https:/www.onepetro.org/journal-paper/SPE-165585-PA. [http://dx.doi.org/10.2118/165585-PA]

[22] S.W. Hawking, “Information Preservation and Weather Forecasting for Black Holes." Jan. 2014. [Online]. Available from: https://arxiv.org/pdf/1401.5761.pdf

[23] K. Cobb, "U.S. Department of Energy: Our forecasts aren't really forecasts (or are they?)." Jan. 2015. [Online]. Available 
from:http://www.resilience.org/stories/ 2015-01-18/u-s-department-of-energy-our-forecasts-aren-t-really-forecasts-or-are-they [Accessed: $18^{\text {th }}$ Jan. 2015]

[24] D.A. Redelmeier, and A. Tversky, "On the belief that arthritis pain is related to the weather", Proc. Natl. Acad. Sci. USA, vol. 93, no. 7, pp. 2895-2896, 1996. [Dec. 17, 2014]. [Online] Available from: http://www.ncbi.nlm.nih.gov/pmc/articles/PMC39730/ [http://dx.doi.org/10.1073/pnas.93.7.2895]

(C) Castro et al.; Licensee Bentham Open.

This is an open access article licensed under the terms of the Creative Commons Attribution-Non-Commercial 4.0 International Public License (CC BY-NC 4.0) (https://creativecommons.org/licenses/by-nc/4.0/legalcode), which permits unrestricted, non-commercial use, distribution and reproduction in any medium, provided the work is properly cited. 